\title{
Bacterial community dissimilarity between the surface and subsurface soils equals horizontal differences over several kilometers in the western Tibetan Plateau
}

\author{
Haiyan Chu, ${ }^{1 *}$ Huaibo Sun, ${ }^{2}$ Binu M. Tripathi, ${ }^{3}$ \\ Jonathan M. Adams, ${ }^{3}$ Rong Huang, ${ }^{1}$ \\ Yangjian Zhang ${ }^{4}$ and Yu Shi ${ }^{1 *}$ \\ ${ }^{1}$ State Key Laboratory of Soil and Sustainable \\ Agriculture, Institute of Soil Science, Chinese Academy \\ of Sciences, East Beijing Road 71, Nanjing 210008, \\ China. \\ ${ }^{2}$ Novogene Bioinformatics Institute, Beijing 100083, \\ China. \\ ${ }^{3}$ Department of Biological Sciences, Seoul National \\ University, Gwanak, Seoul 151, South Korea. \\ ${ }^{4}$ Key Laboratory of Ecosystem Network Observation \\ and Modeling, Institute of Geographic Sciences and \\ Natural Resources Research, Chinese Academy of \\ Sciences, Beijing 100101, China.
}

\section{Summary}

Many studies have investigated patterns in the nearsurface soil microbial community over large spatial scales. However, less is known about variation in subsurface (15-30 cm of depth) microbial communities. Here we studied depth profiles of microbial communities in high-elevation soils from Tibet. The relative abundance of Acidobacteria, Chloroflexi and Alphaproteobacteria was higher in near-surface layers, while the relative abundance of Actinobacteria, Gemmatimonadetes and Betaproteobacteria was higher in the subsurface samples. The microbial community structure was distinct between the surface and subsurface soil layers, strongly correlating with variation in total carbon (TC) and carbon to nitrogen ratio $(\mathrm{C} / \mathrm{N})$. The differences in the microbial community between the layers were about the same as the horizontal differences between sites separated by many kilometers. Overall, we found that $\mathrm{TC}$ and $\mathrm{C} / \mathrm{N}$ were the best predictors for both surface and subsurface microbial community distribution.

Received 22 March, 2015; Revised: 22 December, 2015; accepted 18 January, 2016. *For correspondence. E-mail: hychu@issas.ac. cn; Tel. 86-25-86881356; Fax +086-025-86881000. E-mail: yshi@ issas.ac.cn; Tel. 86-25-86881310; Fax +086-025-86881000.
Exploration of the relative contribution of distance and environmental variables to community composition suggests that the contemporary environment is the primary driver of microbial distribution in this region. Reflecting niche conservatism in evolution, the microbial communities in each soil site and layer tended to be more phylogenetically clustered than expected by chance, and surface soil layer samples were more likely to be clustered than subsurface samples.

\section{Introduction}

Patterns of soil microbial community distribution have been well documented in many studies (Fierer and Jackson, 2006; Lauber et al., 2009; Chu et al., 2010; Griffiths et al., 2011). These studies focused exclusively on the nearsurface layer $(0-10 \mathrm{~cm})$, in which soil microorganisms were always present in the densest populations and where they were collectively most active (Fierer et al., 2003). However, there is no doubt that the role of subsurface soil microorganisms in soil nutrition cycling, soil respiration and ecosystem function is also important (Wardle, 2006; Wardle et al., 2006; Wagg et al., 2014; Zhou et al., 2014), and the soil formation, ecosystem biochemical processes, contaminant degradation, as well as groundwater maintenance can be affected by these subsoil microbes (Konopka and Turco, 1991; Hiebert and Bennett, 1992; Madsen, 1995; Richter and Markewitz, 1995; Fierer et al., 2003; Li et al., 2014). Because its environments are distinct from those of surface soils (Fritze et al., 2000; Blume et al., 2002; Fierer et al., 2003; Li et al., 2014), the subsurface soil may contain different sets of microbial communities (Fierer et al., 2003). However, little is known about the geographic distribution patterns of subsurface soil microbial communities. Understanding these patterns will provide useful baseline information for explaining subsurface soil biological process.

Many published studies on the microbial composition of surface and subsurface soil layers have focused on a few sites, or just a single location (Fierer et al., 2003; LaMontagne et al., 2003; Goberna et al., 2006; Xiang et al., 2008; 


\section{$1524 H$. Chu et al.}

Serkebaeva et al., 2013; Li et al., 2014). Fierer et al. (2003) and LaMontagne et al. (2003) found that the composition of soil microbial communities was significantly different between different soil depths, and suggested the most plausible explanation was that the characteristics and properties of the different soil layers were markedly different. However, these studies only included a few sites or small areas, and the driving factors for microbial distribution in different soil layers over large scale geographic distances are still unknown.

It is widely known that surface soil microorganisms can disperse globally (Finlay, 2002; Fenchel, 2003) and proliferate in any habitat which has suitable environmental conditions (Green et al., 2008). For example, the availability of nutrients and water (Hansel et al., 2008), soil pH (Fierer and Jackson, 2006; Lauber et al., 2009; Chu et al., 2010; Griffiths et al., 2011) and the soil C/N ratios (Xiong et al., 2010; Zhang et al., 2014) can all influence the microbial community structure. In addition, soil temperature (Miller et al., 2009), moisture (Angel et al., 2010), nutrient availability (Orwin et al., 2006) and other abiotic factors can also affect the microbial community composition, as do biotic factors such as local plant species diversity (Mitchell et al., 2010) and regional differences in vegetation types (Kowalchuk et al., 2002; Eisenhauer et al., 2010; Knief et al., 2010; Zhang et al., 2010; Chu et al., 2011). Recently, various studies have found that spatial distance has a strong influence on the distribution of surface microbial communities (Cho and Tiedje, 2000; Whitaker et al., 2003; Xiong et al., 2012). Specifically, Cho and Tiedje (2000) provided one of the first examples where the genetic similarity of free-living bacteria decreased with geographic distance, pointing to the effects of various limitations that affected the bacterial dispersal. Other studies found that the current environment (e.g., local environments with specific geochemistry, resulting in distinct soil characteristics) or historical events (including dispersal limitation, past environmental conditions and spatial distance) that might influence the present-day microbial assemblages, had significant impacts on surface soil microbial distributions (Borcard et al., 1992; Martiny et al., 2006; Ramette and Tiedje, 2007; Martiny et al., 2011). For example, some studies found that soil $\mathrm{pH}$ (a present-day factor) played an important role in shaping the microbial community distribution pattern over large spatial scales (Fierer and Jackson, 2006; Lauber et al., 2009; Chu et al., 2010; Griffiths et al., 2011), while Ramette and Tiedje (2007) found that the impacts of historical contingencies on microbial communities are likely correlated with spatial distance (historical events). However, there is almost no knowledge about the pattern of subsurface soil microbial distribution on a large scale. Furthermore, we do not know whether the soil microbial community similarity between the surface and subsurface soil at a single site will be greater or less than the community difference between different sites that are spaced hundreds of kilometers apart. Increasing numbers of studies use a phylogenetic framework to reveal underground biodiversity and biogeographic patterns based on 16S rRNA gene surveys (Webb, 2000; Bryant et al., 2008; Vamosi et al., 2009). This method can illustrate the importance of different ecological and evolutionary processes which affect the community composition. Macro-organisms including plants (Bryant et al., 2008), hummingbirds (Graham et al., 2009), ants (Machac et al., 2011) and bees (Hoiss et al., 2012) have been well studied using the phylogenetic framework. Recently, some studies have also investigated the phylogenetic patterns of microorganisms in different habitats (Wang et al., 2013; Shen et al., 2013), but we do not yet know the phylogenetic clustering patterns of soil microbial communities in surface and subsurface soils on a large scale.

Ngari, the highest, driest and coldest region in the western Tibetan Plateau, has been named the "arid core" of the Asiatic Plateau (Troll, 1972). The low intensities of human disturbance and the extreme soil conditions may promote soil bacterial communities that are distinct from those in low elevation areas. The mainly non-anthropogenic conditions make this region an ideal setting to study natural soil microbial distributions at different soil depths. Here, using 454 pyrosequencing of samples taken at two soil depths $(0-15 \mathrm{~cm}$ as the surface soil and $15-30 \mathrm{~cm}$ as the subsurface soil) at 12 sites, we compare the soil microbial community composition of surface and subsurface soils in this unique and ecologically fragile area.

Our major hypotheses were:

i. That in terms of microbial community similarity, being in the same soil profile (even if soil parameters are different) prevails over environmental similarity (similar soil physical/chemical parameters) of widely spatially scattered samples. It is expected that the dispersal limitation effect of geographic distance on the bacterial community similarity will operate more strongly than soil geochemistry.

ii. That the major environmental driving factors for the surface and subsurface soil microbial community composition are different. We expected that the subsurface soil geochemistry would be different enough that different measurable environmental variables would be more important in producing depth differences in microbial communities, compared to horizontal geographic differences.

iii. That phylogenetic clustering of the microbial community in the upper soil layer is stronger than that in the subsurface soil layer. It is expected that closely related lineages of bacteria will, predictably, occur together because of niche conservatism. If the role of dispersal limitation and randomness is greater, the 


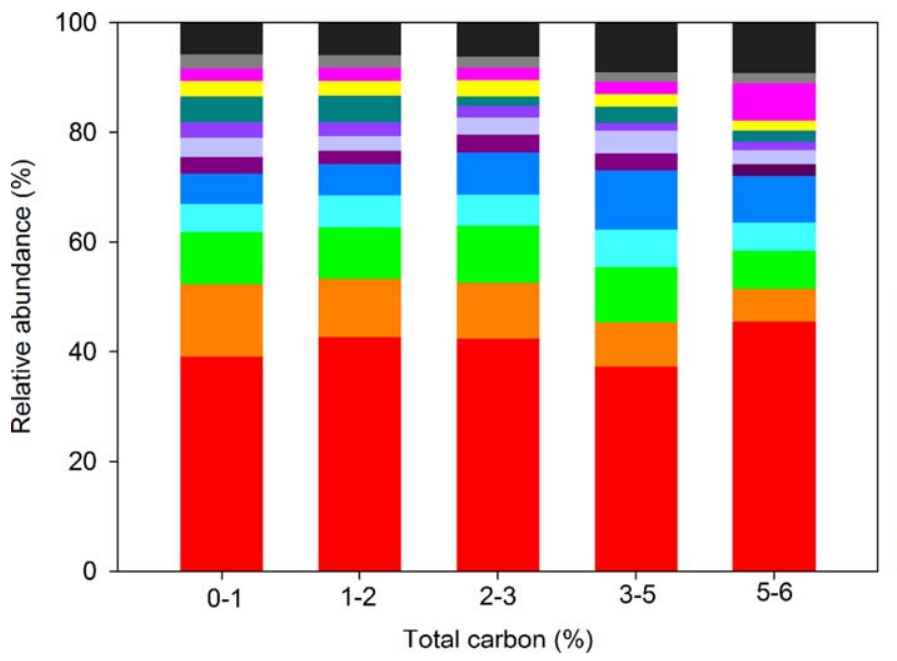

resulting soil communities should show less of this orderly clustering of related lineages. We hypothesized that the bacteria occurring in lower soil layers are 'cut off' from effective dispersal and adjustment of their distributions to prevailing soil conditions hence, in this layer there will be less evidence of the predictable effects of environment in terms of phylogenetic clustering.

\section{Results}

A total of 119,507 16S rRNA V4 and V5 sequences (mostly bacteria and a few archaea) were obtained across 24 soil samples (two depths [0-15 cm and 15-30 cm] from 12 sites [five soil cores within a $100 \mathrm{~m}^{2}$ of area combined as one sample representing each depth]). From this pyrosequencing data, we annotated 6515 operational taxonomic units (OTUs: 97\% identity). The dominant phyla/ classes included Actinobacteria ( 40\%), Alphaproteobacteria ( 10\%), Acidobacteria ( 10\%), Gemmatimonadetes ( $\sim 7 \%$ ) and Chloroflexi ( $\sim 5.5 \%$ ), accounting for more than $70 \%$ of the total sequence data (Fig. 1 and Supporting Information Table S1). Across the 12 sites, Actinobacteria were higher in the subsurface samples by a factor of $4.26 \pm 3.14$ in 8 out of 12 paired surface-subsurface soils, and Gemmatimonadetes and Betaproteobacteria were at higher levels in the subsurface samples by factors of $2.75 \pm 1.86$ and $1.3 \pm 0.71$ in 10 out of 12 , respectively (Supporting Information Fig. S1). Alphaproteobacteria were more prevalent in the surface samples by $2.26 \pm 1.94$ in 7 out of 12 paired surface-subsurface soils, Acidobacteria and Chloroflexi were higher in the surface samples by factors of $1.68 \pm 0.69$ and $1.24 \pm 0.67$ in 8 out of 12 , and Firmicutes were higher in the surface samples by a factor of $2.83 \pm 2.31$ in 10 out of 12 (Supporting Information Fig. S1).
Fig. 1. Relative abundance of the dominant bacterial phyla/classes and archaeal phyla across the soils. Soils are grouped by total soil carbon.
Non-metric multidimensional scaling plots (NMDS) showed that the microbial community structure of surface and subsurface soils in the Ngari was clearly divided (Fig. 2). The ANOSIM analysis further confirmed that the soil microbial community in the surface soils was significantly different from that in subsurface soils $(R=0.37$, $P=0.001)$. More interestingly, by calculating pairwise Bray-Curtis dissimilarity, we found that the microbial community difference between the two layers from within a single site (0-15 cm vs. 15-30 cm, separated by a few centimeters), was about the same as the average dissimilarity between one site and the other sites at the same soil depth, even though they were many kilometers apart (Supporting Information Fig. S2 and Table S2).

There was a clear bacterial community difference between the different soil layers (Fig. 2). Upon testing for role of environmental variables, no factors were found

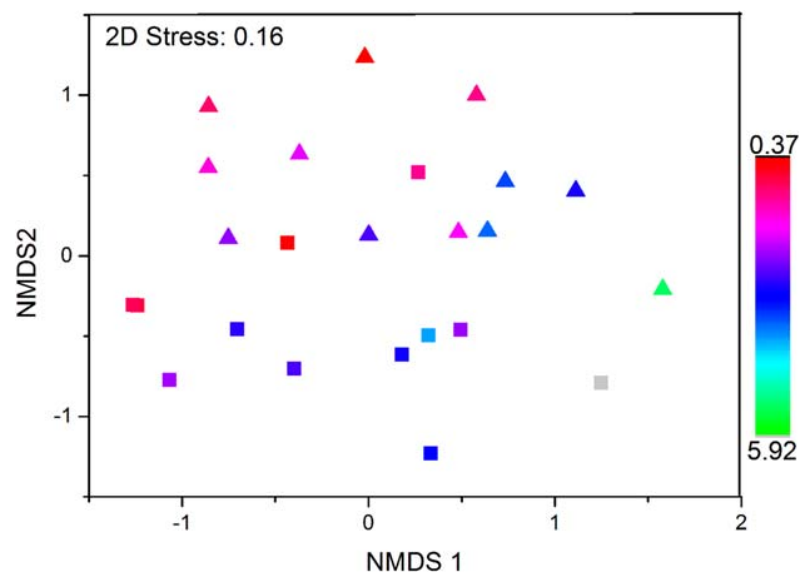

Fig. 2. Bacterial community compositional structure in the Ngari soils as indicated by non-metric multidimensional scaling plots. Sites are color coded according to the total soil carbon content. The filled triangles represent $0-15 \mathrm{~cm}$ of soils and filled squares represent $15-30 \mathrm{~cm}$ of soils. 
which accounted for these differences. To identify the soil properties that could influence bacterial community variation among sites (surface and subsurface soil microbial community data considered together), canonical correspondence analysis (CCA) was performed. This analysis showed that the bacterial community from all the samples could be best explained by soil total carbon and $\mathrm{C} / \mathrm{N}$ ratio (Supporting Information Fig. S3). This interpretation was supported by matrix correlation analysis between the bacterial community structures and soil total carbon (TC) and $\mathrm{C} / \mathrm{N}$ (Supporting Information Table S3). A Mantel test showed that the soil TC was the factor which most strongly influenced the bacterial community composition in all the samples (Supporting Information Table S3) and NMDS results showed that the bacterial community was distributed along a TC gradient (Fig. 2) in the western Tibetan Plateau. Other soil factors such as $\mathrm{pH}$ and moisture also showed significant correlation with the bacterial community structure. In this study, the strong influences of soil TC and $\mathrm{C} / \mathrm{N}$ were evident even at the coarse level of taxonomic resolution of the dominant phyla/class (Gemmatimonadetes and Deltaproteobacteria) in surface soil and Planctomycetes in the two layers (Supporting Information Table S4). Together, these results strongly suggest that, separately, the microbial data from the surface and subsurface are strongly affected by $\mathrm{TC}$ and $\mathrm{C} / \mathrm{N}$, and that soil TC also plays an important role in shaping the distribution of the soil microbial community (including in surface and subsurface soils) in the western Tibetan Plateau.

To understand which bacterial phyla mostly contribute to community dissimilarity between the two layers, SIMPER analysis was conducted to identify the contribution of bacterial phylum/class-level differences to the overall community difference. Here, the relative abundance of microbes in the 12 sites' soil were analyzed separately. Next, the contribution and the relative abundance of bacterial phyla/classes were illustrated in a boxplot (Fig. 3). The results revealed that the dominant phyla/classes such as Actinobacteria, Alphaproteobacteria and Gemmatimonadetes, make a greater contribution than other phyla/ classes to the community structure difference between the surface and subsurface soil (Fig. 3 and Supporting Information Table S5). However, although the relative abundance of Acidobacteria was greater than that of Firmicutes, Acidobacteria made a smaller contribution to the community difference. This suggests that high relative abundance of these particular phyla/classes may not result in a correspondingly large contribution to the microbial community dissimilarity between the two layers.

Distinctions in the bacterial community structure between the surface and subsurface soils led us to investigate the soil factors which separately influence the bacterial community distribution between the layers. In the surface soils, we found $\mathrm{TC}, \mathrm{C} / \mathrm{N}$ and $\mathrm{pH}$ strongly influenced

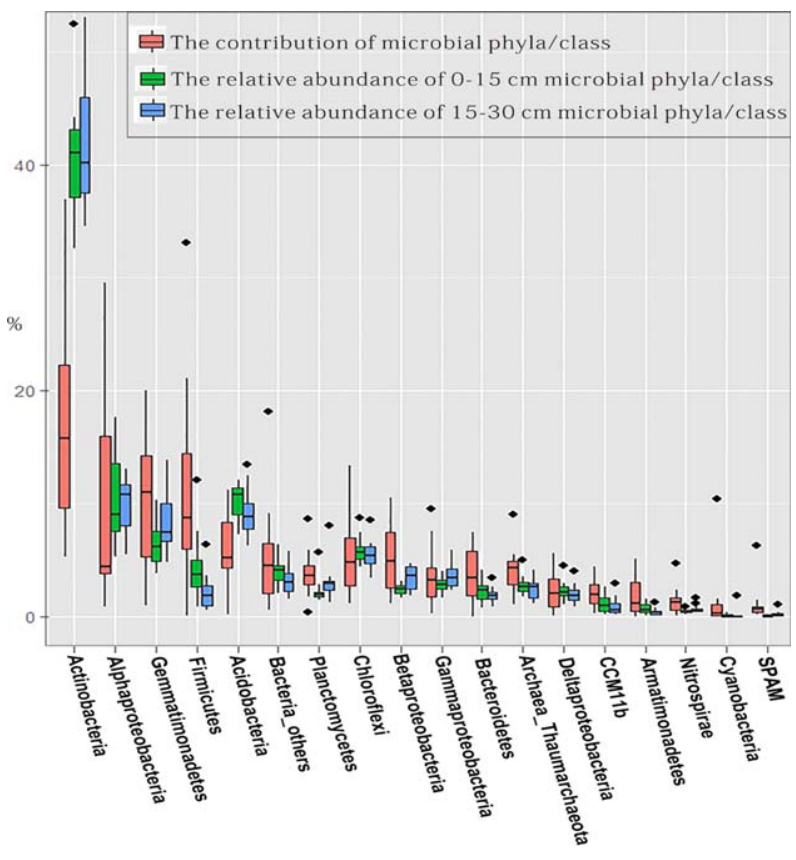

Fig. 3. The contribution of bacterial phyla/classes which generated the community difference between the $0-15$ and $15-30 \mathrm{~cm}$ of soils.

the microbial community distribution (Supporting Information Fig. S4A), which was further confirmed by Mantel test, suggesting that soil TC $(r=0.55, P<0.001)$ could be the main driver of the bacterial community composition (Supporting Information Table S6). In the subsurface soils, TC and $\mathrm{C} / \mathrm{N}$ also strongly influenced the bacterial community structure (Supporting Information Fig. S4B) and TC was the best predictor $(r=0.49, P<0.001)$ of the subsurface bacterial community distribution (Supporting Information Table S6). In addition to $\mathrm{TC}$ and $\mathrm{C} / \mathrm{N}$, soil ammonium was also significantly correlated with the subsurface community composition (Supporting Information Table S6). Other factors might also affect the community composition but not in a consistent and predictable way.

In order to examine whether local environmental factors (contemporary) or spatial distance (historic legacy) exhibited more influence on the microbial community distribution from each of the different soil layers, we explored the relative contributions of geographic distance and environmental variables. Our results showed that the measured soil variables, i.e. environmental factors, had a stronger correlation with the broad-scale surface and subsurface soil bacterial dissimilarities than distance factors (Fig. 4). These results were confirmed by Partial Mantel tests between the environments, spatial distance and bacterial community composition (Supporting Information Table S7). We thus suggest that contemporary factors play a more important role than historical factors in shaping the broadscale bacterial community pattern of both the surface and subsurface soil layers across the western Tibetan Plateau. 

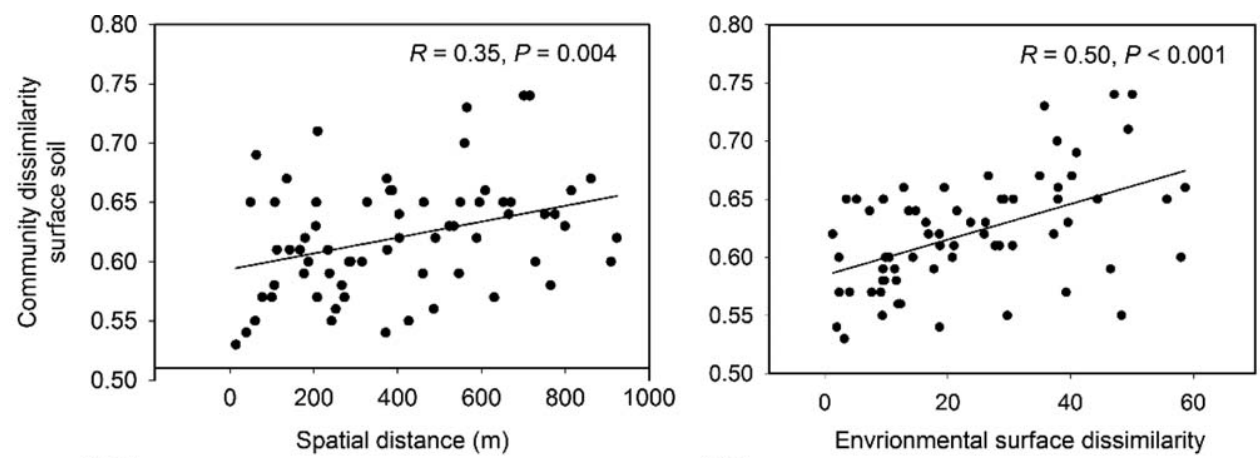

Fig. 4. Relationships between bacterial community, spatial distance and environmental distance.
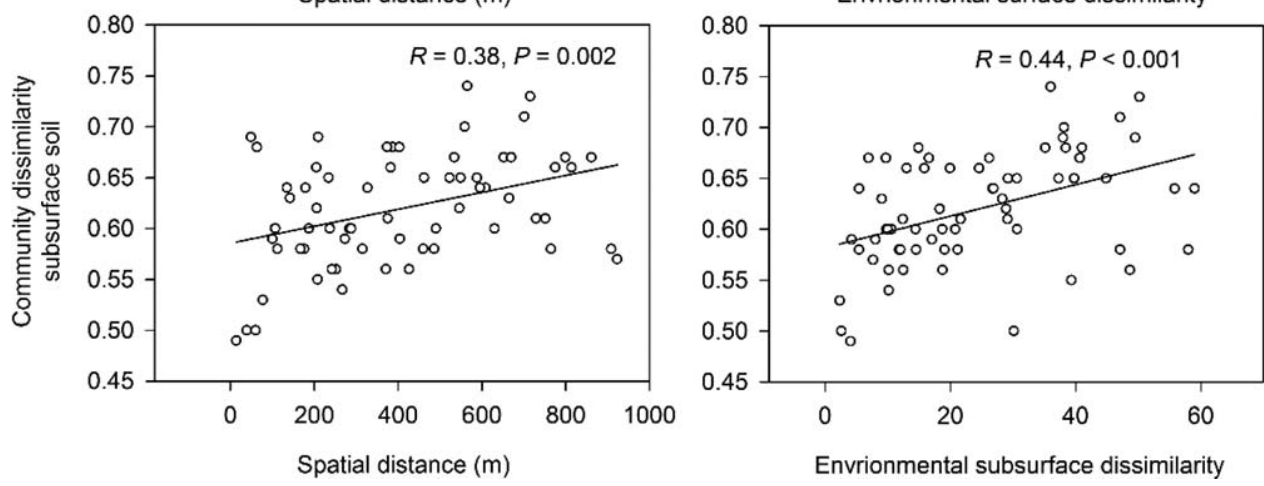

In order to analyze the phylogenetic community composition, mean nearest taxon distance (MNTD) was calculated. NMDS based on MNTD measurements showed that samples were phylogenetically segregated by soil depth (Fig. 5). A permutational multivariate analysis of variance showed that soil depth explained $13.5 \%$ of the variation in phylogenetic community composition ( $P<0.001,9999$ permutations). The MNTD values increased with soil depth ( $t$-test, $P=0.001$; Fig. 6), which indicates that in surface soil layer samples, phylogenetic clustering is stronger than in samples from the subsurface layer. All of the standardized effect sizes of MNTD

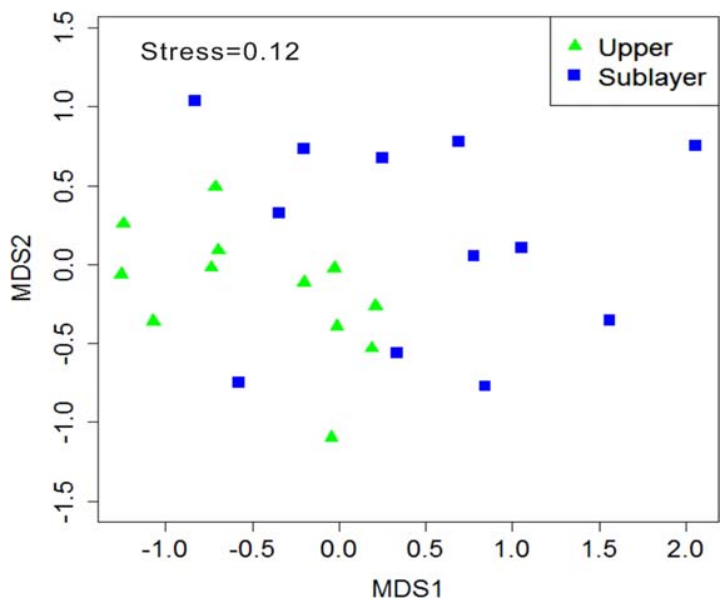

Fig. 5. Non-metric multidimensional scaling plots of community dissimilarities within soil depth groups using betaMNTD.
(ses.MNTD) values obtained using the null model were significantly negative, which shows that the bacterial communities tended to be more phylogenetically clustered than would be expected by chance. Further, the standardized metric showed a similar pattern to that of the MNTD (t-test, $P=0.02$; Fig. 6), which indicates that random effects have only a minor influence on the depth pattern of the bacterial phylogenetic structure.

\section{Discussion}

Our first hypothesis was that the soil microbial community is more likely to cluster vertically on the centimeter scale than to assemble in similar environmental conditions on a large horizontal scale. However, we found that the bacterial community difference between the two soil layers at each site was no different from the average dissimilarity between sites on the horizontal scale. There have been many studies investigating microbial community distribution patterns at scales from centimeters to meters (Franklin and Mills, 2003; Philippot et al., 2009), or at the landscape scale (Yergeau et al., 2009; Bru et al., 2011; Shi et al., 2015). For example, Ramette and Tiedje (2007) reported that the difference in community composition within the Burkholderia bacterial group at small scales (between individual plant roots) was greater than that on large spatial scales (across a field) and they suggested that the community composition at the small scale was mostly related to the surrounding environmental conditions. Thus, the vertical centimeter scale community differences in our study might be caused by differences in 

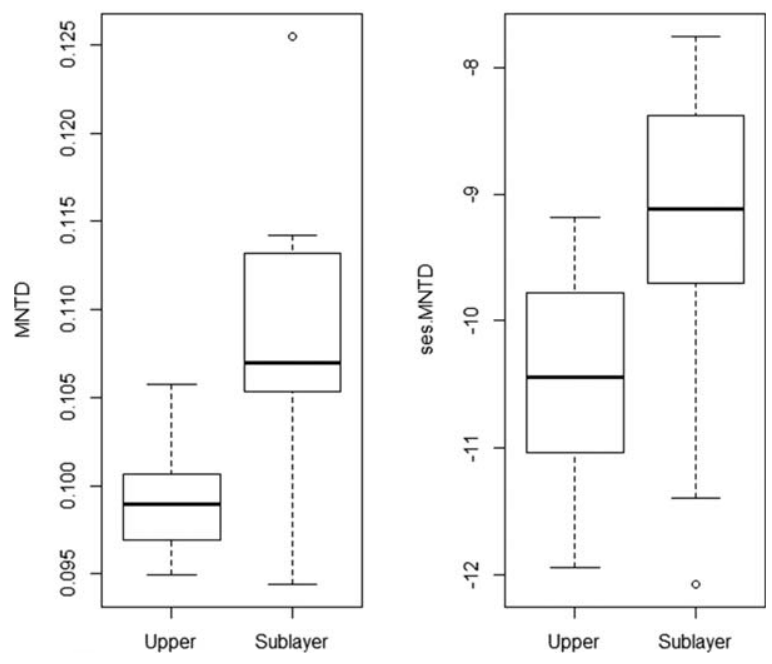

Fig. 6. Variation of mean nearest taxon distance (MNTD) and the standardized effect sizes of MNTD (ses.MNTD) of bacterial communities in upper and sublayer soils.

environmental factors between the soil layers. It is well understood that microbial communities are strongly influenced by soil properties (Fierer and Jackson, 2006; Chu et al., 2010; Griffiths et al., 2011; Shen et al., 2013; Zhang et al., 2014) such as available carbon, $\mathrm{pH}$ and moisture. Interestingly, Smith et al. (1999) found that wind speed and direction could influence the distribution of sewageassociated bacteria. It is also known that microbes can associate with dust, one study found that the distribution dust-associated bacteria and fungi could best be explained by climatic and soil variables (Barberán et al., 2015). Considering this, we suggest that the wind might also drive soil microbial distribution over $\mathrm{cm}$ or $\mathrm{km}$ spatial scales in the dry, cold Ngari. In this study, the microbial community varies in relation to several identifiable parameters, including horizontal space (Fig. 2), TC (Figs. 2, Supporting Information Figs. S3 and S4), C/N (Supporting Information Figs. S3 and S4), moisture (Supporting Information Fig. S3), pH (Supporting Information Figs. S3 and S4), and ammonia concentration (Supporting Information Fig. S4). Because of low temperatures and limited $\mathrm{N}$ availability, organic matter in Tibetan soils decomposes relatively slowly (Yang et al., 2008) and differences in soil temperature between different layers will result in different decomposition rates. Several factors $\left(\mathrm{TN}, \mathrm{NH}_{4}^{+}-\mathrm{N}, \mathrm{NO}_{3}^{-}-\mathrm{N}\right.$ and DON) differed between the two soil layers and between sites (Table 1). Possibly, these differences in vertical soil conditions (on the centimeter scale) had a stronger influence in altering soil microbial community composition of surface and subsurface soil than they did over distances of many kilometers horizontally

We also hypothesized that vertical variation in the soil microbial community, between near-surface and subsur- face soil layers within the same profiles, would be influenced by different parameters when compared to samples separated horizontally between sites. Contrary to our assumption, although the microbial community composition differed between the surface and subsurface soils, the community structure was driven by similar soil parameters, i.e., TC and C/N. We found soil carbon to be a robust predictor for both surface and subsurface soil microbial community distribution. In other studies, available carbon substrates usually decreased with soil depth, presumably because of the reduced input of plant litter and root exudates (Blume et al., 2002; Fierer et al., 2003; LaMontagne et al., 2003). However, while we found that $\mathrm{TN}, \mathrm{NH}_{4}^{+}-\mathrm{N}$, $\mathrm{NO}_{3}^{-}-\mathrm{N}$ and DON in the surface soil were higher than in the subsurface soil, we did not find any difference in total soil $\mathrm{C}$ between the surface and subsurface soil (Table 1). The reason might be that the soil microbial community was more strongly limited by the soil TN and available nitrogen in different layers, with $\mathrm{N}$ causing the variation in community with depth.

In this study, we found the dominant phyla/classes Actinobacteria, Alphaproteobacteria and Gemmatimonadetes contributed most to the difference in bacterial communities between the surface and subsurface soil (Fig. 3). These phyla/classes comprised nearly $60 \%$ of the total sequences. Actinobacteria can produce a wide variety of antibiotics (Berdy, 2005; Manivasagan et al., 2013), and have been found to be predominant in alkaline Tibetan soils (Zhang et al., 2014), consistent with our results that more alkaline soils had a higher relative abundance of Actinobacteria (Table 1). Alphaproteobacteria are mostly fast growing and preferred nutrient-rich soil environments (Fierer and Jackson, 2006; Lauber et al., 2009; Chu et al., 2010; Shi et al., 2015). However, in this study, the relative abundance of Alphaproteobacteria decreased with increasing carbon conditions $(\mathrm{C} / \mathrm{N}, \mathrm{DOC})$ in surface soils (Supporting Information Table S4), which might be caused by the limited $\mathrm{N}$ availability in the Tibetan Plateau (Yang et al., 2008). Gemmatimonadetes, identified as one of the top nine phyla found in soils (DeBruyn et al., 2011), and suggested to live particularly in low soil moisture conditions (Janssen, 2006), showed positively correlation with the surface soil TC and DOC (Supporting Information Table S4). However, high relative abundance did not always equate to a high contribution to the difference between layers. For example, Acidobacteria had higher relative abundance than the Gemmatimonadetes in the soils, but Gemmatimonadetes were more important in producing differences in the communities.

In order to determine whether the distribution of soil bacteria in different soil layers in the Ngari was controlled more by dispersal limitation or habitat environment, we compared the relationship between the bacterial community dissimilarity, environmental difference and spatial 
Table 1. Description of the soil variables by study site. DON, dissolved organic nitrogen; TN, total nitrogen; SM, soil moisture content; TC, total carbon content; $\mathrm{DOC}$, dissolved organic carbon; $\mathrm{C} / \mathrm{N}$, carbon and nitrogen ratio; $\mathrm{NH}_{4}^{+}$, ammonium; $\mathrm{NO}_{3}^{-}$, nitrate. A represents surface soil and $B$ represents subsurface soil.

\begin{tabular}{|c|c|c|c|c|c|c|c|c|c|c|c|c|}
\hline Sample name & Latitude & Longitude & Elevation (m) & $\mathrm{pH}$ & SM (\%) & TC (\%) & TN (\%) & $\mathrm{C} / \mathrm{N}$ & $\begin{array}{l}\text { DOC } \\
(\mathrm{mg} / \mathrm{kg})\end{array}$ & $\begin{array}{l}\text { DON } \\
(\mathrm{mg} / \mathrm{kg})\end{array}$ & $\begin{array}{l}\mathrm{NH}_{4}^{+} \\
(\mathrm{mg} / \mathrm{kg})\end{array}$ & $\begin{array}{l}\mathrm{NO}_{3}^{-} \\
(\mathrm{mg} / \mathrm{kg})\end{array}$ \\
\hline $1-A$ & $N 31^{\circ} 22^{\prime} 28^{\prime \prime}$ & $\mathrm{E} 90^{\circ} 23^{\prime} 57^{\prime \prime}$ & 4628 & 8.51 & 10.43 & 0.95 & 0.14 & 6.86 & 84.8 & 2.34 & 5.79 & 6.23 \\
\hline $2-A$ & $N 31^{\circ} 23^{\prime} 26^{\prime \prime}$ & $\mathrm{E} 90^{\circ} 14^{\prime} 55^{\prime \prime}$ & 4658 & 8.49 & 11 & 1.49 & 0.19 & 7.71 & 65.1 & 3.91 & 5.36 & 6.47 \\
\hline $3-A$ & $\mathrm{~N} 31^{\circ} 31^{\prime} 20^{\prime \prime}$ & $\mathrm{E} 89^{\circ} 45^{\prime} 17^{\prime \prime}$ & 4594 & 9.01 & 8.4 & 2.92 & 0.07 & 44.43 & 63.8 & 1.96 & 2.61 & 0.98 \\
\hline $4-A$ & $N 32^{\circ} 30^{\prime} 55^{\prime \prime}$ & $\mathrm{E} 88^{\circ} 56^{\prime} 16^{\prime \prime}$ & 4990 & 8.48 & 8.72 & 2.33 & 0.16 & 14.27 & 164.9 & 2.84 & 2.84 & 3.82 \\
\hline $5-A$ & $N 33^{\circ} 11^{\prime} 57^{\prime \prime}$ & E88 $48^{\prime} 37^{\prime \prime}$ & 4965 & 8.62 & 6.64 & 1.88 & 0.14 & 13.68 & 94.5 & 4.5 & 6.75 & 4.71 \\
\hline $6-A$ & $\mathrm{~N} 33^{\circ} 17^{\prime} 42^{\prime \prime}$ & E88 $24^{\prime} 24^{\prime \prime}$ & 4853 & 8.55 & 8.63 & 2.66 & 0.21 & 12.83 & 152.8 & 5.2 & 5.63 & 7.48 \\
\hline $7-A$ & 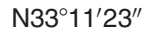 & $\mathrm{E} 86^{\circ} 53^{\prime} 18^{\prime \prime}$ & 4650 & 8.92 & 1.4 & 1.13 & 0.02 & 56.61 & 98.4 & 2.62 & 3.02 & 3.43 \\
\hline 8-A & $N 32^{\circ} 10^{\prime} 03^{\prime \prime}$ & $\mathrm{E} 84^{\circ} 39^{\prime} 58^{\prime \prime}$ & 4433 & 8.85 & 9.04 & 3.52 & 0.1 & 35.93 & 140.9 & 1.42 & 2.4 & 1.86 \\
\hline $9-A$ & $\mathrm{~N} 32^{\circ} 14^{\prime} 03^{\prime \prime}$ & $\mathrm{E} 84^{\circ} 01^{\prime} 43^{\prime \prime}$ & 4521 & 9.04 & 8.11 & 3.66 & 0.13 & 27.37 & 271.7 & 2.79 & 5.26 & 3.33 \\
\hline $10-A$ & $N 32^{\circ} 22^{\prime} 50^{\prime \prime}$ & $E 82^{\circ} 4^{\prime} 33^{\prime \prime}$ & 4459 & 8.21 & 7.72 & 5.31 & 0.14 & 37.06 & 244.6 & 3.43 & 5.36 & 3.54 \\
\hline $11-A$ & $N 32^{\circ} 04^{\prime} 24^{\prime \prime}$ & $\mathrm{E} 81^{\circ} 49^{\prime} 36^{\prime \prime}$ & 4601 & 8.66 & 5.31 & 1.71 & 0.09 & 19.87 & 272.8 & 2.1 & 1.89 & 1.36 \\
\hline $12-\mathrm{A}$ & $N 32^{\circ} 20^{\prime} 54^{\prime \prime}$ & $\mathrm{E} 80^{\circ} 40^{\prime} 43^{\prime \prime}$ & 4751 & 8.41 & 3.33 & 0.37 & 0.04 & 8.33 & 48.5 & 2.55 & 2.96 & 3.16 \\
\hline $1-B$ & $N 31^{\circ} 22^{\prime} 28^{\prime \prime}$ & $\mathrm{E} 90^{\circ} 23^{\prime} 57^{\prime \prime}$ & 4628 & 8.43 & 9.9 & 0.75 & 0.1 & 7.29 & 45.8 & 3.29 & 3.4 & 2.41 \\
\hline $2-B$ & $N 31^{\circ} 23^{\prime} 26^{\prime \prime}$ & $\mathrm{E} 90^{\circ} 14^{\prime} 55^{\prime \prime}$ & 4658 & 8.6 & 7.47 & 0.87 & 0.08 & 10.24 & 75.9 & 1.95 & 2.7 & 1.4 \\
\hline 3-B & $\mathrm{N} 31^{\circ} 31^{\prime} 20^{\prime \prime}$ & $\mathrm{E} 89^{\circ} 45^{\prime} 17^{\prime \prime}$ & 4594 & 8.95 & 8.39 & 3.1 & 0.06 & 48.12 & 109.9 & 0.98 & 1.96 & 0.87 \\
\hline 4-B & $N 32^{\circ} 30^{\prime} 55^{\prime \prime}$ & $\mathrm{E} 88^{\circ} 56^{\prime} 16^{\prime \prime}$ & 4990 & 8.55 & 10.68 & 2.26 & 0.11 & 21.51 & 543 & 1.57 & 2.35 & 1.68 \\
\hline $5-B$ & N33ํำ $11^{\prime} 57^{\prime \prime}$ & E88 $48^{\circ} 37^{\prime \prime}$ & 4965 & 8.58 & 11.35 & 2.85 & 0.15 & 19.38 & 61.7 & 1.67 & 3.01 & 1.34 \\
\hline $6-B$ & $N 33^{\circ} 17^{\prime} 42^{\prime \prime}$ & E88 $24^{\prime} 24^{\prime \prime}$ & 4853 & 8.63 & 9.91 & 2.67 & 0.15 & 17.61 & 152.3 & 2.85 & 3.18 & 2.08 \\
\hline 7-B & N33⒈ $11^{\prime} 23^{\prime \prime}$ & $\mathrm{E} 86^{\circ} 53^{\prime} 18^{\prime \prime}$ & 4650 & 8.91 & 4.25 & 1.17 & 0.03 & 45.21 & 246.9 & 0.83 & 1.66 & 0.83 \\
\hline 8-B & N32 $10^{\prime} 03^{\prime \prime}$ & E84 $39^{\prime} 58^{\prime \prime}$ & 4433 & 8.74 & 8.99 & 3.97 & 0.11 & 36.19 & 272 & 1.31 & 2.28 & 0.76 \\
\hline 9-B & $N 32^{\circ} 14^{\prime} 03^{\prime \prime}$ & $\mathrm{E} 84^{\circ} 01^{\prime} 43^{\prime \prime}$ & 4521 & 8.98 & 4.19 & 2.96 & 0.04 & 65.89 & 219.4 & 0.41 & 2.27 & 1.24 \\
\hline $10-B$ & $N 32^{\circ} 22^{\prime} 50^{\prime \prime}$ & $\mathrm{E} 82^{\circ} 4^{\prime} 33^{\prime \prime}$ & 4459 & 8.61 & 6.22 & 5.92 & 0.1 & 57.04 & 111.6 & 2.34 & 1.49 & 2.55 \\
\hline $11-B$ & $N 32^{\circ} 04^{\prime} 24^{\prime \prime}$ & $\mathrm{E} 81^{\circ} 49^{\prime} 36^{\prime \prime}$ & 4601 & 8.28 & 6.05 & 2.28 & 0.09 & 26.64 & 27.1 & 1.16 & 2.64 & 1.06 \\
\hline $12-B$ & N32 $20^{\prime} 54^{\prime \prime}$ & $\mathrm{E} 80^{\circ} 40^{\prime} 43^{\prime \prime}$ & 4751 & 8.55 & 2.7 & 0.46 & 0.06 & 7.98 & 119.7 & 0.91 & 2.84 & 1.52 \\
\hline
\end{tabular}

distance. Although environmental factors were the stronger predictors of community composition, we also observed a significant distance-decay relationship for bacterial community structure at both soil depths. Dispersal limitation and variation in past environmental conditions may contribute to the patterns of spatial variability in microbial communities (Cho and Tiedje, 2000; Green et al., 2004; Martiny et al., 2006; Martiny et al., 2011), because changes in environmental conditions over time may generate significant biogeographical endemism within microbial communities, and these contingencies could increase with spatial distance among communities (Chu et al., 2010; Martiny et al., 2006). However, some studies have suggested that the environment is more important than spatial distance in shaping bacterial community distribution in soils in America (Fierer and Jackson, 2006), Britain (Griffiths et al., 2011) and the Arctic (Chu et al., 2010). Our results suggest that both the local environment and historic factors influence the microbial spatial pattern in surface and subsurface soils, but the contemporary environment is the primary driver in the western Tibetan Plateau.

In this study, we found that samples were phylogenetically segregated by soil depth. In both surface and subsurface soils, the ses.MNTD distribution mean deviated significantly from zero, indicating that bacterial assemblages had significantly higher phylogenetic clustering than would be expected by chance, which suggests that communities were structured by environmental filtering. This result is consistent with several previous studies in various habitats (Casamayor and Barberán, 2010; Stegen et al., 2012; Wang et al., 2013), which showed that microbial communities tend to be phylogenetically clustered. Furthermore, phylogenetic clustering was stronger in surface soils than in subsurface soils, which may be related to the increased importance of environmental filtering in surface soils. These results were similar to the Bray-Curtis distances of the Ngari microbial biogeographic pattern. Together, our results suggest that bacterial community samples from the surface and subsurface soil layers presented similar or greater differences than samples from the same layers kilometers apart, revealing the overwhelming importance of environmental factors in determining microbial community variation on both scales.

\section{Experimental procedures}

\section{Soil sampling}

We collected soil samples at 12 study sites over a broad area $\left(\sim 300,000 \mathrm{~km}^{2}\right)$ in the northwest of Tibet, China (Supporting Information Fig. S5) during July to August 2011. At each site, the upper $15 \mathrm{~cm}$ of soil was collected from five random locations within a given plot of $\sim 100 \mathrm{~m}^{2}$ and composited into a single soil sample, while the corresponding $15-30 \mathrm{~cm}$ of soil 


\section{$1530 H$. Chu et al.}

was collected at the same time and then mixed together. All soil samples were shipped on ice packs $\left(4^{\circ} \mathrm{C}\right)$ to the lab as soon as possible, where they were stored at $-20^{\circ} \mathrm{C}$ until processing.

\section{Soil description}

Soil for $\mathrm{C}$ and $\mathrm{N}$ analyses was air dried, sieved (2 $\mathrm{mm}$ mesh), handpicked to remove fine roots, ground, and then determined by combustion (CNS-2000; LECO, St. Joseph, MI, USA) (Supporting Information Table S1). Soil moisture was measured gravimetrically after a $10 \mathrm{~h}$ desiccation at $105^{\circ} \mathrm{C}$. Soil $\mathrm{pH}$ was determined with a fresh soil to water ratio of $1: 5$ by $\mathrm{pH}$ monitor (Thermo Orion-868) (Supporting Information Table S1). All the sites were located by GPS (Table 1). Dissolved organic carbon (DOC), dissolved total nitrogen (DTN), ammonium $\left(\mathrm{NH}_{4}^{+}-\mathrm{N}\right)$ and nitrate $\left(\mathrm{NO}_{3}^{-}-\mathrm{N}\right)$ were determined as described (Chu et al., 2010) (Supporting Information Table S1).

\section{4 pyrosequencing}

To compare the bacterial diversity and community structure from surface and subsurface soils, we used 454 pyrosequencing. Soil DNA was extracted from $0.5 \mathrm{~g}$ of fresh soil following the Power Soil kit (MO BIO Laboratories, Carlsbad, CA, USA) procedure. The primer F515, GTGCCAGCMGCCGCGG, with the Roche 454'A' pyrosequencing adapter and a unique $7 \mathrm{bp}$ bar-code sequence, and primer R907, CCGTCAATTCMTTTRAGTTT, with the Roche 454'B' sequencing adapter at the 5 '-end of each primer, were used for amplification of the V4-V5 hyper variable regions of bacterial 16S rRNAs (most bacteria and a few archaea). In this study, a few archaeal sequences $(<3 \%)$ were also recovered. Each sample was amplified in triplicate in a $50 \mu \mathrm{l}$ reaction with the following conditions: 30 cycles of denaturation at $94^{\circ} \mathrm{C}$ for $30 \mathrm{~s}$, annealing at $55^{\circ} \mathrm{C}$ for $30 \mathrm{~s}$ and extension at $72^{\circ} \mathrm{C}$ for $30 \mathrm{~s}$, with a final extension at $72^{\circ} \mathrm{C}$ for $10 \mathrm{~min}$. PCR products from each sample were pooled together and purified with agarose gel DNA purification kits (TaKaRa), combined in equimolar ratios in a single tube and run on a Roche FLX454 pyrosequencing machine (Roche Diagnostics Corporation, Branford, CT, USA).

\section{Data analysis}

Raw sequence data were processed and analyzed using the quantitative insight into microbial ecology (QIIME) pipeline (http://qiime.sourceforge.net/) (Caporaso et al., 2010). Reads which were $<200$ bp long or had an average quality score $<25$ were removed (Huse et al., 2007). Clustering of quality sequences into operational taxonomic units (OTUs) was generated through UCLUST based on a $97 \%$ similarity level (Edgar, 2010). The taxonomic identity of each phylotype was determined using the Greengenes database (http://greengenes.lbl.gov/). In this study, 2900 sequences per sample (OTU-table 2900) were randomly selected to calculate the Bray-Curtis (Bray and Curtis, 1957) dissimilarity between each pair of samples. Faith's index (Faith, 1992) was used to determine the phylogenetic diversity and the richness (i.e., number) of phylotypes for each sample and was calculated using the OTU-table 2900. SPSS 20.0 was used to compare the correlations between microbial diversity and soil variables. Mantel test were calculated using the microbial dissimilarity matrix and environmental dissimilarity matrix, where microbial dissimilarity were calculated based on the Bray Curtis method using the OTU table and the environmental dissimilarity was calculated based on the Euclidean method using the soil variables' table. Here, all the environmental variables were normalized before the calculation, and factors' autocorrelation were tested using envfit (in the vegan package) before analysis, only variables with no autocorrelation were included in calculating the environmental dissimilarity. In order to test the relationship between the microbial community and each environmental factor, we also calculated the dissimilarity of one environmental factor (eg.TC) among the sites. Non-metric multidimensional scaling analyses (NMDS) were performed on the Bray-Curtis dissimilarity for the microbial community data (OTU-table 2900). Canonical corresponding analysis (CCA) was conducted between microbial community data (OTU-table 2900) and soil variables. The Mantel test, SIMPER analysis (Clarke, 1993), NMDS and CCA analysis were conducted using the vegan package (Dixon, 2003) $\mathrm{R} \times 64$ 3.0.1 (http://cran.stat.sfu.ca/).

To quantify phylogenetic turnover in community composition between a given pair of samples (i.e., 'phylobetadiversity'), we used mean nearest taxon distance (MNTD) separating OTUs into two communities (Fine et al., 2011; Stegen et al., 2012). MNTD is the mean phylogenetic distance to the closest relative in a paired community for all taxa (Fine et al., 2011) and is sensitive to changes of lineage close to the phylogenetic tips. We performed non-metric multidimensional scaling based on MNTD measures to depict community composition in two dimensions. To test that soil depth structure distribution of bacteria, permutational multivariate analysis of variance was used (Anderson et al., 2001).

To evaluate the degree of non-random phylogenetic community structure, OTUs and their relative abundances were randomized across the tips of phylogeny (null.model = 'taxa.labels' in 'ses.mntd'). The standardized effect size measure (ses.MNTD) quantifies the number of standard deviations that the observed MNTD is from the mean of the null distribution (999 randomizations). The obtained ses.MNTD can be used to test for phylogenetic clustering or over dispersion (Webb, 2000). Negative ses.MNTD values and low quantiles $(P<0.05)$ indicate that co-occurring species are more closely related than expected by chance (clustering), whereas positive values and high quantiles $(P>0.95)$ indicate that the co-occurring species are less closely related than expected by chance (over dispersion) (Webb et al., 2000). These analyses were implemented in the $R$ environment (http://www.r-project.org) with the package Picante 1.2-0 (Kembel et al., 2010).

Sequences generated in this study have been deposited in the European Molecular Biology Laboratory (EMBL) database under accession number ERP009919 (http://www.ebi.ac.uk/ ena/data/search?query=ERP009919).

\section{Acknowledgements}

We thank Yingying Ni, Congcong Shen and Xingjia Xiang for their assistance in lab analysis. This work was supported by the National Program on Key Basic Research Project 
(2014CB954002), the Strategic Priority Research Program (XDB15010101) of the Chinese Academy of Sciences, and the National Natural Science Foundation of China (41371254).

\section{References}

Anderson, M.J. (2001) A new method for non-parametric multivariate analysis of variance. Aust Ecol 26: 32-46.

Angel, R., Soares, M.I.M., Ungar, E.D., and Gillor, O. (2010) Biogeography of soil archaea and bacteria along a steep precipitation gradient. ISME J 4: 553-563.

Barberán, A., Ladau, J., Leff, J.W., Pollard, K.S., Menninger, H.L., Dunn, R.R., and Fierer, N. (2015) Continental-scale distributions of dust-associated bacteria and fungi. Proc Natl Acad Sci U S A 112: 5756-5761.

Berdy, J. (2005) Bioactive microbial metabolites. J Antibiot 58: 1-26.

Blume, E., Bischoff, M., Reichert, J.M., Moorman, T., Konopka, A., and Turco, R.F. (2002) Surface and subsurface microbial biomass, community structure and metabolic activity as a function of soil depth and season. Appl Soil Ecol 20: 171-181.

Borcard, D., Legendre, P., and Drapeau, P. (1992) Partialling out the spatial component of ecological variation. Ecology 73: 1045-1055.

Bray, J.R., and Curtis, J.T. (1957) An ordination of the upland gorest communities of southern Wisconsin. Ecol Monogr 27: 326-349.

Bru, D., Ramette, A., Saby, N.P.A., Dequiedt, S., Ranjard, L., Jolivet, C., et al. (2011) Determinants of the distribution of nitrogen-cycling microbial communities at the landscape scale. ISME J 5: 532-542.

Bryant, J.A., Lamanna, C., Morlon, H., Kerkhoff, A.J., Enquist, B.J., and Green J.L. (2008) Microbes on mountainsides: Contrasting elevational patterns of bacterial and plant diversity. Proc Natl Acad Sci U S A 105: 11505-11511.

Caporaso, J.G., Kuczynski, J., Stombaugh, J., Bittinger, K., Bushman, F.D., Costello, E.K., et al. (2010) QIIME allows analysis of high-throughput community sequencing data. Nat Methods 7: 335-336.

Casamayor, E.O., and Barberán, A. (2010) Global phylogenetic community structure and $\beta$-diversity patterns in surface bacterioplankton metacommunities. Aquat Microbial Ecol 59: 1-10.

Cho, J.C., and Tiedje, J.M. (2000) Biogeography and degree of endemicity of fluorescent Pseudomonas strains in soil. Appl Environ Microbiol 66: 5448-5456.

Chu, H.Y., Fierer, N., Lauber, C.L., Caporaso, J.G., Knight, R., and Grogan, P. (2010) Soil bacterial diversity in the Arctic is not fundamentally different from that found in other biomes. Environ Microbiol 12: 2998-3006.

Chu, H.Y., Neufeld, J.D., Walker, V.K., and Grogan, P. (2011) The influence of vegetation type on the dominant soil bacteria, archaea, and fungi in a low arctic Tundra Landscape. Soil Sci Soc Am J 75: 1756-1765.

Clarke, K.R. (1993) Non-parametric multivariate analyses of changes in community structure. Aust $J$ Ecol 18: 117143.

DeBruyn, J.M., Nixon, L.T., Fawaz, M.N., Johnson, A.M., and Radosevich, M. (2011) Global Biogeography and quantita- tive seasonal dynamics of gemmatimonadetes in soil. Appl Environ Microbiol 77: 6295-6300.

Dixon, P. (2003) VEGAN, a package of R functions for community ecology. J Veget Sci 14: 927-930.

Edgar, R.C. (2010) Search and clustering orders of magnitude faster than BLAST. Bioinformatics 26: 2460-2461.

Eisenhauer, N., Bessler, H., Engels, C., Gleixner, G., Habekost, M., Milcu, A., et al. (2010) Plant diversity effects on soil microorganisms support the singular hypothesis. Ecology 91: 485-496.

Faith, D.P. (1992) Conservation evaluation and phylogenetic diversity. Biol Conserv 61: 1-10.

Fenchel, T. (2003) Microbiology: biogeography for bacteria. Science 301: 925-926.

Fierer, N., and Jackson, R.B. (2006) The diversity and biogeography of soil bacterial communities. Proc Natl Acad Sci U S A 103: 626-631.

Fierer, N., Schimel, J.P., and Holden, P.A. (2003) Variations in microbial community composition through two soil depth profiles. Soil Biol Biochem 35: 167-176.

Fine, P.V.A., and Kembel, S.W. (2011) Phylogenetic community structure and phylogenetic turnover across space and edaphic gradients in western Amazonian tree communities. Ecography 34: 552-565.

Finlay, B.J. (2002) Global dispersal of free-living microbial eukaryote species. Science 296: 1061-1063.

Franklin, R.B., and Mills, A.L. (2003) Multi-scale variation in spatial heterogeneity for microbial community structure in an eastern Virginia agricultural field. Fems Microbiol Ecol 44: 335-346.

Fritze, H., Pietikainen, J., and Pennanen, T. (2000) Distribution of microbial biomass and phospholipid fatty acids in Podzol profiles under coniferous forest. Eur J Soil Sci 51: 565-573.

Goberna, M., Sanchez, J., Pascual, J.A., and Garcia, C. (2006) Surface and subsurface organic carbon, microbial biomass and activity in a forest soil sequence. Soil Biol Biochem 38: 2233-2243.

Graham, C.H., Parra, J.L., Rahbek, C., and McGuire, J.A. (2009) Phylogenetic structure in tropical hummingbird communities. Proc Natl Acad Sci U S A 106: 19673-19678.

Green, J.L., Holmes, A.J., Westoby, M., Oliver, I., Briscoe, D., Dangerfield, M., et al. (2004) Spatial scaling of microbial eukaryote diversity. Nature 432: 747-750.

Green, J.L., Bohannan, B.J.M., and Whitaker, R.J. (2008) Microbial biogeography: from taxonomy to traits. Science 320: 1039-1043.

Griffiths, R.I., Thomson, B.C., James, P., Bell, T., Bailey, M., and Whiteley, A.S. (2011) The bacterial biogeography of British soils. Environ Microbiol 13: 1642-1654.

Hansel, C.M., Fendorf, S., Jardine, P.M., and Francis, C.A. (2008) Changes in bacterial and archaeal community structure and functional diversity along a geochemically variable soil profile. Appl Environ Microbiol 74: 1620-1633.

Hiebert, F.K., and Bennett, P.C. (1992) Microbial control of silicate weathering in organic-rich ground water. Science (Washington DC) 258: 278-281.

Hoiss, B., Krauss, J., Potts, S.G., Roberts, S., and SteffanDewenter, I. (2012) Altitude acts as an environmental filter on phylogenetic composition, traits and diversity in bee communities. Proc $R$ Soc London Ser B Biol 279: 4447-4456. 
Huse, S.M., Huber, J.A., Morrison, H.G., Sogin, M.L., and Welch, D.M. (2007) Accuracy and quality of massively parallel DNA pyrosequencing. Genome Biol 8: R143.

Janssen, P.H. (2006) Identifying the dominant soil bacterial taxa in libraries of 16S rRNA and 16S rRNA genes. Appl Environ Microbiol 72: 1719-1728.

Kembel, S.W., Cowan, P.D., Helmus, M.R., Cornwell, W.K., Morlon, H., Ackerly, D.D., et al. (2010) Picante: R tools for integrating phylogenies and ecology. Bioinformatics 26: 1463-1464.

Konopka, A., and Turco, R. (1991) Biodegradation of organic compounds in vadose zone and aquifer sediments. Appl Environ Microbiol 57: 2260-2268.

Knief, C., Ramette, A., Frances, L., Alonso-Blanco, C., and Vorholt, J.A. (2010) Site and plant species are important determinants of the Methylobacterium community composition in the plant phyllosphere. ISME J 4: 719-728.

Kowalchuk, G.A., Buma, D.S., Boer, W.de, Klinkhamer, P.G., and Van Veen., J.A. (2002) Effects of above-ground plant species composition and diversity on the diversity of soilborne microorganisms. Antonie Van Leeuwenhoek 81: 509-520.

LaMontagne, M.G., Schimel, J.P., and Holden, P.A. (2003) Comparison of subsurface and surface soil microbial communities in California grassland as assessed by terminal restriction fragment length polymorphisms of PCR-amplified 16S rRNA genes. Microb Ecol 46: 216-227.

Lauber, C.L., Hamady, M., Knight, R., and Fierer, N. (2009) Pyrosequencing-based assessment of soil $\mathrm{pH}$ as a predictor of soil microbial community structure at the continental scale. Appl Environ Microbiol 75: 5111-5120.

Li, C.H., Yan, K., Tang, L.S., Jia, Z.J., and Li, Y. (2014) Change in deep soil microbial communities due to longterm fertilization. Soil Biol Biochem 75: 264-272.

Machac, A., Janda, M., Dunn, R.R., and Sanders, N.J. (2011) Elevational gradients in phylogenetic structure of ant communities reveal the interplay of biotic and abiotic constraints on diversity. Ecography 34: 364-371.

Madsen, E. (1995) Impacts of agricultural practices on subsurface microbial ecology. Adv Agron 54: 1-67.

Manivasagan P., Venkatesan J., Sivakumar K., and Kim S.K. (2013) Marine actinobacterial metabolites: current status and future perspectives. Microbiol Res 168: 311-332.

Martiny, J.B.H., Bohannan, B.J.M., Brown, J.H., Colwell, R.K., Fuhrman, J.A., Green, J.L., et al. (2006) Microbial biogeography: putting microorganisms on the map. Nat Rev Microbiol 4: 102-112.

Martiny, J.B.H., Eisen, J.A., Penn, K., Allison, S.D., and Horner-Devine, M.C. (2011) Drivers of bacterial betadiversity depend on spatial scale. Proc Natl Acad Sci U S A 108: 7850-7854.

Miller, S.R., Strong, A.L., Jones, K.L., and Ungerer, M.C. (2009) Bar-coded pyrosequencing reveals shared bacterial community properties along the temperature gradients of two alkaline hot springs in Yellowstone National Park. Appl Environ Microbiol 75: 4565-4572.

Mitchell, R.J., Campbell, C.D., Chapman, S.J., and Cameron, C.M. (2010) The ecological engineering impact of a single tree species on the soil microbial community. $J$ Ecol 98: 50-61.
Orwin, K.H., Wardle, D.A., and Greenfield, L.G. (2006) Ecological consequences of carbon substrate identity and diversity in a laboratory study. Ecology 87: 580-593.

Philippot, L., Cuhel, J., Saby, N.P.A., Cheneby, D., Chronakova, A., Bru, D., Arrouays, D., Martin-Laurent, F., and Simek, M. (2009) Mapping field-scale spatial patterns of size and activity of the denitrifier community. Environ Microbiol 11: 1518-1526.

Ramette, A., and Tiedje, J.M. (2007) Multiscale responses of microbial life to spatial distance and environmental heterogeneity in a patchy ecosystem. Proc Natl Acad Sci U S A 104: 2761-2766.

Richter, D., and Markewitz, D. (1995) How deep is soil? BioScience 45: 600-609.

Serkebaeva, Y.M., Kim, Y., Liesack, Y.W, and Dedysh, S.N. (2013) Pyrosequencing-based assessment of the bacteria diversity in surface and subsurface peat layers of a northern wetland, with focus on poorly studied phyla and candidate divisions. Plos One 8: 1-14.

Shen, C.C., Xiong, J.B., Zhang, H.Y., Feng, Y.Z., Lin, X.G., Li, X.Y., et al. (2013) Soil pH drives the spatial distribution of bacterial communities along elevation on Changbai Mountain. Soil Biol Biochem 57: 204-211.

Shi, Y., Xiang, X.J., Shen, C.C., Chu, H.Y., Neufeld, J.D., Walker, V.K., and Grogan, P. (2015) Vegetation-associated impacts on Arctic tundra bacterial and micro-eukaryotic communities. Appl Environ Microbiol 81: 482-501.

Smith, P., Carroll, C., Wilkins, B., Johnson, P., Gabhainn, S.N., and Smith, L.P. (1999) The effect of wind speed and direction on the distribution of sewage-associated bacteria. Lett Appl Microbiol 28: 184-188.

Stegen, J.C., Lin, X., Konopka, A.E., and Fredrickson, J.K. (2012) Stochastic and deterministic assembly processes in subsurface microbial communities. ISME J 6: 16531664.

Troll, C. (1972) The three-dimensional zonation of the Himalaya system. In Geoecology of the High Mountain Regions in Eurasia. Vol. 4. Troll, C. (ed.). Wiesbaden, Germany: Erdwissenschaftliche Forschung.Franz Steiner Verlag, pp. 264-275.

Vamosi, S.M., Heard, S.B., Vamosi, J.C., and Webb, C.O. (2009) Emerging patterns in the comparative analysis of phylogenetic community structure. Mol Ecol 18: 572-592.

Wagg, C., Bender, S.F., Widmer, F., and van der Heijden, M.G.A. (2014) Soil biodiversity and soil community composition determine ecosystem multifunctionality. Proc Natl Acad Sci U S A 111: 5266-5270.

Wang, J., Shen, J., Wu, Y., Tu, C., Soininen, J., Stegen, J.C., et al. (2013) Phylogenetic beta diversity in microbial assemblages across ecosystems: deterministic versus stochastic processes. ISME J 7: 1310-1321.

Wardle, D.A. (2006) The influence of biotic interactions on soil biodiversity. Ecol Lett 9: 870-886.

Wardle, D.A., Yeates, G.W., Barker, G.M., and Bonner, K.I. (2006) The influence of plant litter diversity on decomposer abundance and diversity. Soil Biol Biochem 38: 1052-1062.

Webb, C.O. (2000) Exploring the phylogenetic structure of ecological communities: an example for rain forest trees. Am Nat 156: 145-155.

Whitaker, R.J., Grogan, D.W., and Taylor, J.W. (2003). Geographic barriers isolate endemic populations of hyperthermophilic archaea. Science 301: 976-978. 
Xiang, S.R., Doyle, A., Holden, P.A., and Schimel, J.P. (2008) Drying and rewetting effects on $\mathrm{C}$ and $\mathrm{N}$ mineralization and microbial activity in surface and subsurface California grassland soils. Soil Biol Biochem 40: 22812289.

Xiong, J.B., Wu, L.Y., Tu, S.X., Van Nostrand, J.D., He, Z.L., Zhou, J.Z., and Wang, G.J. (2010) Microbial communities and functional genes associated with soil arsenic contamination and the rhizosphere of the arsenic-hyperaccumulating plant Pteris vittata L. Appl Environ Microbiol 76: 72777284.

Xiong, J.B., Liu, Y.Q., Lin, X.G., Zhang, H.Y., Zeng, J., Hou, J.Z., et al. (2012) Geographic distance and pH drive bacterial distribution in alkaline lake sediments across Tibetan Plateau. Environ Microbiol 14: 2457-2466.

Yang, Y.H., Fang, J.Y., Tang, Y.H., Ji, C.J., Zheng, C.Y., He, J.S., and Zhu, B. (2008) Storage, patterns and controls of soil organic carbon in the Tibetan grasslands. Global Change Biol 14: 1592-1599.

Yergeau, E., Schoondermark-Stolk, S.A., Brodie, E.L., Dejean, S., DeSantis, T.Z., Goncalves, O., et al. (2009). Environmental microarray analyses of Antarctic soil microbial communities. ISME J 3: 340-351.

Zhang, C.B., Wang, J., Liu, W.L., Zhu, S.X., Ge, H.L., Chang, S.X., et al. (2010) Effects of plant diversity on microbial biomass and community metabolic profiles in a full-scale constructed wetland. Ecol Eng 36: 62-68.

Zhang, X.F., Xu, S.J., Li, C.M., Zhao, L., Feng, H.Y., Yue, G.Y., et al. (2014) The soil carbon/nitrogen ratio and moisture affect microbial community structures in alkaline permafrost-affected soils with different vegetation types on the Tibetan plateau. Res Microbiol 165: 128139.

Zhou, J.Z., Deng, Y., Zhang, P., Xue, K., Liang, Y.T., Van Nostrand, J.D., et al. (2014) Stochasticity, succession, and environmental perturbations in a fluidic ecosystem. Proc Natl Acad Sci U S A 111: E836-E845.

\section{Supporting information}

Additional Supporting Information may be found in the online version of this article at the publisher's web-site:

Fig. S1. Relative abundance of the dominant bacterial phyla/classes in $0-15 \mathrm{~cm}$ and $15-30 \mathrm{~cm}$ soil from each site. A represents surface soil and B represents subsurface soil.
Fig S2. Horizontal and vertical comparison of the community comparison dissimilarity. Firstly, the Bray-Curtis dissimilarity matrix was calculated between the paired sites. The average of dissimilarity values were then calculated between each site, and between other sites for the same layer.

Fig S3. Canonical corresponding analysis (CCA) of bacterial community composition and environmental variables. A is the $0-15 \mathrm{~cm}$ soil and $B$ is $15-30 \mathrm{~cm}$ soil.

Fig S4. Canonical corresponding analysis (CCA) of bacterial community composition and environmental variables. A is $0-15 \mathrm{~cm}$ soil and $B$ is $15-30 \mathrm{~cm}$ soil.

Fig. S5. Locations of sampling sites.

Table S1. Average relative abundances of phyla/classes classified using the Greengenes database (http://greengenes.lbl.gov/) across all soils and soils grouped by soil total carbon (\%). Phyla/classes in the first column are a combination of multiple OTUs.

Table S2. Geographic distance between the soil sampling sites $(\mathrm{km})$.

Table S3. The correlations $(r)$ and significance $(P)$ were determined by Mantel tests between the community structure and environmental variables. DON: dissolved organic nitrogen; TN: total nitrogen; SM: soil moisture content; TC: total carbon content; DOC: dissolved organic carbon; $\mathrm{C} / \mathrm{N}$ : carbon to nitrogen ratio; $\mathrm{NH}_{4}^{+}$: ammonium, $\mathrm{NO}_{3}^{-}$: nitrate.

Table S4. The correlations ( $r$ ) were determined by Pearson Correlation between the dominant phyla and environmental variables. DON: dissolved organic nitrogen; TN: total nitrogen; SM: soil moisture content; TC: total carbon content; DOC: dissolved organic carbon; $\mathrm{C} / \mathrm{N}$ : carbon and nitrogen ratio; $\mathrm{NH}_{4}^{+}$: ammonium, $\mathrm{NO}_{3}^{-}$: nitrate. Values in bold are significant at $\mathrm{P}<0.05$

Table S5. SIMPER analysis of the contribution of bacterial phyla/class to the difference between the $0-15 \mathrm{~cm}$ and 15 $30 \mathrm{~cm}$ soils. Up: the relative abundance of $0-15 \mathrm{~cm}$ soil bacterial phyla/class. Down: the relative abundance of $15-30 \mathrm{~cm}$ soil bacterial phyla/class.

Table S6. The correlations $(r)$ and significance $(P)$ determined by Mantel tests between community structure and environmental variables. DON: dissolved organic nitrogen; TN: total nitrogen; SM: soil moisture content; TC: total carbon content; DOC: dissolved organic carbon; $\mathrm{C} / \mathrm{N}$ : carbon and nitrogen ratio; $\mathrm{NH}_{4}^{+}$: ammonium, $\mathrm{NO}_{3}^{-}$: nitrate.

Table S7. Mantel tests and Partial tests were conducted to compare the relative impact of environments and spatial distance on the bacterial community. 